\title{
BMJ Open Psychometric properties of the Chinese version of the spiritual care competency scale in nursing practice: a methodological study
}

\author{
Yanli Hu, ${ }^{1}$ René Van Leeuwen, ${ }^{2}$ Fan Li (D) ${ }^{1,2,3,4,5,6,7}$
}

To cite: Hu Y, Leeuwen RV, Li F. Psychometric properties of the Chinese version of the spiritual care competency scale in nursing practice: a methodological study. BMJ Open 2019;9:e030497. doi:10.1136/ bmjopen-2019-030497

- Prepublication history and additional material for this paper are available online. To view these files, please visit the journal online (http://dx.doi. org/10.1136/bmjopen-2019030497).

Received 20 March 2019 Revised 04 September 2019 Accepted 05 September 2019

Check for updates

(C) Author(s) (or their employer(s)) 2019. Re-use permitted under CC BY-NC. No commercial re-use. See rights and permissions. Published by BMJ.

For numbered affiliations see end of article.

Correspondence to

Professor Fan Li;

lifan@jlu.edu.cn

\section{ABSTRACT}

Objectives To determine the validity and reliability of the Spiritual Care Competency Scale (SCCS) among nurses in China.

Design Methodological research.

Methods After the SCCS was translated into Chinese, the validity and reliability of the Chinese version of the SCCS (C-SCCS) were evaluated using a convenience sample of 800 nurses recruited from different healthcare centres. The construct validity of the C-SCCS was determined by an exploratory factor analysis (EFA) with promax rotation. Pearson's correlation coefficients of the C-SCCS and the Palliative Care Spiritual Care Competency Scale (PCSCCS-M) were computed to assess the concurrent validity and construct validity of the C-SCCS. To verify the quality of the component structure, we conducted a confirmatory factor analysis (CFA). We tested the internal consistency and stability of the measure using Cronbach's alpha coefficient and the Guttman split-half coefficient, respectively, and a factorial analysis was performed. Results A total of 709 participants completed the questionnaire (response rate: $88.63 \%$ ), and all completed questionnaires were suitable for analysis. Three factors were abstracted from the EFA and explained $58.19 \%$ of the total variance. The Cronbach's alpha coefficients of the three subscales were $.93, .92$, and .89, and the Guttman split-half coefficient for the C-SCCS was .84. The CFA indicated a well-fitting model, and the significant correlations between the C-SCCS and the PCSCCS-M $(r=0.67, p<0.01)$ showed adequate concurrent validity. Nurses' education and income level showed a significant association with the C-SCCS score.

Conclusion The C-SCCS was shown to be a psychometrically sound instrument for evaluating Chinese nurses' spiritual care competencies.

\section{INTRODUCTION}

Although the debate on the definition of spiritual care is long-standing, spiritual care in the present study refers to "recognising and responding to the needs of the human spirit when the individual is facing trauma, illness or sadness, and addressing individuals' need for satisfactory meaning, selfworth, self-expression, the support of faith, the practice of rituals, prayers or sacraments
Strengths and limitations of this study

- The Chinese version of the Spiritual Care Competency Scale (C-SCCS) demonstrated good psychometric properties, enabling the assessment of nursing students' and registered nurses' ability to provide spiritual care for patients.

- The sample size enabled us to determine that the C-SCCS has the ability to discriminate between different subgroups.

- The sample of nurses was mainly from two provinces in China and was obtained using a convenience sampling method; therefore, the findings may not be representative of all nurses in China.

- Further testing in a larger sample is required to explore the details of and reasons for the association between nurses' demographic variables and the three factors of the C-SCCS.

- Further analysis using multiple methods would help to establish the stability of this instrument.

and conversation with sensitive listeners'. ${ }^{1-11}$ Spiritual care is viewed as an essential and core element of holistic nursing care and has been integrated into nursing education and nursing practice, ${ }^{12-16}$ as it can improve patients' quality of life and health outcomes. ${ }^{6-18}$ Optimal spiritual care relies largely on nurses' adequate preparedness to provide it, because nurses are thought to be competent in caring for the spiritual needs of patients ${ }^{19}$ and are the chief providers of spiritual care to patients. A close relationship exists between nurses' ability to provide spiritual care to patients and the fulfilment of patients' spiritual needs. ${ }^{20-23}$ Being competent in the delivery of such care is regarded as one of nurses' primary professional skills. ${ }^{18}$

Research has found that medical personnel who have undergone spiritual care training are more likely to meet patients' spiritual needs when providing spiritual care. ${ }^{24-26}$ In recent years, palliative care practices for clinical symptoms, physical and mental reactions, 
family support and spiritual care for malignant tumour patients in a Chinese context have been reported, though such reports are rare. Indeed, in China, nursing students' awareness of palliative care and spiritual care remains low. In the practice of palliative care, practitioners recognise the importance of early palliative and spiritual care education for nursing students. Therefore, educational curricula for teaching palliative and spiritual care to nursing students is gradually being developed. However, many clinical nurses feel poorly prepared to provide care in this area. This is due largely to the lack of spiritual care education provided in junior and undergraduate nursing programmes resulting from a lack of specific content, guidelines and evaluation criteria for providing spiritual care education. ${ }^{27}$

Thus, one issue that needs to be addressed is the current level of nurses' spiritual care competencies and which aspects nurses are expected to acquire or improve to provide such care for patients. Therefore, it is necessary to assess nurses' existing competency levels to determine to what extent they should receive relevant education and training, which would enable them to explore the resources available to assist patients in improving their health and life satisfaction. ${ }^{28}{ }^{29}$ A number of instruments have been developed to evaluate these competencies in some countries, such as the Spiritual Care Competency Scale (SCCS) ${ }^{18}$ the Student Survey of Spiritual Care $(\mathrm{SSSC})^{30}$ and the Palliative Care Spiritual Care Competency Scale (PCSCCS) ${ }^{31}$ However, there is no comprehensive instrument available in mainland China, and little is known about Chinese nurses' capabilities in this regard and the effects of spiritual care in practice. This issue needs to be addressed urgently to inform the education and training sectors.

The SCCS, a self-reported scale first invented by van Leeuwen et $a l^{18}$ measures student nurses' abilities to provide spiritual care to patients. The tool was developed based on the nursing competency profile. ${ }^{32}$ The assessed competencies were first mentioned by van Leeuwen and Cusveller $^{32}$ in a qualitative literature review and were then confirmed by Baldacchino ${ }^{33}$ in a study performed among nurses. The SCCS has been used with nurses and has sound validity and reliability. As there is no mature spiritual care ability assessment tool for nurses in China, we choose the SCCS scale, which has good reliability and validity for translation and cultural adaptation, and test the reliability and validity of the Chinese translation of the SCCS in a representative sample of Chinese-speaking nurses. It is hoped that this study will provide references for the measurement, assessment and development of Chinese nurses' spiritual care competencies.

\section{METHODS}

\section{Participants}

The study sample consisted of Chinese-speaking nurses working in hospitals in China. They were asked to participate in this cross-sectional study to validate the Chinese version of the SCCS (C-SCCS). Convenience sampling (ie, the selection of the sample was mainly determined by the investigator and targeted different departments to improve the recruitment of potential participants: a convenience sample of 13 departments from across Henan and Jilin provinces with nurse managers were recruited through their connections with members of the larger study team) was used to collect the data. ${ }^{34}$ Eight hundred nurses were recruited from 10 healthcare contexts (3 university-affiliated comprehensive hospitals, 2 tumour hospitals, 1 psychiatric hospital, 2 traditional Chinese medicine hospitals, 1 maternal and child health service care centre and 1 community health service centre). There were no exclusion criteria. Data were collected between March and April 2018. A total of 709 nurses completed the survey (response rate: $88.62 \%$ ).

We obtained informed written consent from every participant; we explained the purpose of the study, informed participants of their right not to participate and to withdraw at any time and specified that this study included no identifying details.

\section{Instruments}

The instrument used in this research comprised three parts.

\section{A socialdemographic form}

This form consisted of five questions about participants' age, gender, education, working years and work department. These data demonstrated that the participants recruited comprised a representative sample of individuals of different backgrounds.

\section{The Spiritual Care Competency Scale}

The original 27-item SCCS was developed by van Leeuwen et al. ${ }^{18}$ It uses a 5-point Likert scale to evaluate students' or nurses' competency level in spiritual care, with the response options ranging from 1 (strongly disagree) to 5 (strongly agree). There are six distinct domains of the SCCS: assessment and implementation of spiritual care, professionalisation and improvement of the quality of spiritual care, personal support and patient counselling, referral to professionals, attitude towards patients' spirituality and communication. The Cronbach's alphas of these domains are $0.82,0.82,0.81,0.79,0.56$ and 0.71 , respectively, with good internal consistency among the subscales.

\section{The Chinese mainland version of the Palliative Care Spiritual Care Competency Scale}

The 18-item Chinese version of the PCSCCS, developed by Chen $e t a l^{31}$ and translated by $\mathrm{Hu} e t a l,{ }^{35}$ measures palliative care with respect to professionals' self-reported competencies in providing spiritual care in Taiwan. $\mathrm{Hu}$ et $a \hat{l}^{55}$ verified that the PCSCCS-M can be applied to groups of nurses in areas other than palliative care to measure nurses' spiritual care ability, and the results showed good reliability and validity for a wide range of nursing fields. Therefore, the PCSCCS-M may have a 
large range of applications. It contains three distinct components: knowledge and skills regarding spiritual care (Cronbach's alpha: 0.81); self-awareness and attitude towards spiritual care (Cronbach's alpha: 0.89) and spiritual care that meets patients' spiritual needs (Cronbach's alpha: 0.87). Although differences exist between the PCSCCS-M used in the present study and the SCCS (the PCSCCS was developed based on palliative caregivers and the PCSCCS-M has good validity and reliability in samples of clinical nurses, while the SCCS was developed to assess the spiritual care competencies of nursing students), both measurement tools address spiritual care. Therefore, the PCSCCS-M was chosen to test the C-SCCS's concurrent validity.

\section{Translation and adaptation procedures and psychometric testing}

We translated the SCCS into Chinese according to Brislin's established translation model. ${ }^{36}$ Permission was obtained from Dr van Leeuwen, who developed the original SCCS. Phase I involved four steps. The first step consisted of the forward translation process, in which two translators, one from Jilin University and the other from Naval Medical University, independently translated the scale from English into Chinese. Then, a native speaker of Chinese who also had English fluency and who was not involved in the forward translation process was invited to reconcile the two forward translations. The second step involved back-translation, in which two experts with fluency in English and Chinese (one had studied and worked in an English-speaking country for many years and one has been teaching English for many years in a university of China) translated the reconciled Chinese version back into English. Dr van Leeuwen compared the back-translation with the original version of the SCCS and made any necessary revisions, based on which the final Chinese translation was established.

Phase II consisted of two steps. In the first step, the revised version of the SCCS was pilot tested to evaluate whether the SCCS was easy to understand and complete. The pilot took place in three Jilin University-affiliated teaching hospitals with a convenience sample of 20 nurses (with $>5$ years of working experience in different departments). Second, the psychometric properties of the C-SCCS were determined, including its face validity, item analysis, construct validity, concurrent validity, internal consistency reliability and stability, as represented by the split-half reliability. The construct validity of the C-SCCS was determined by performing an exploratory factor analysis (EFA) with promax rotation. Concurrent validity is when the results of a test using the targeted instrument are compared with those of other effective tests using another valid measuring method at the same or a similar time by adopting the quantitative method of calculating the correlation coefficient. The higher the correlation coefficient is, the greater the validity of the scale. The general validity should be between 0.4 and $0.7 .^{37}$ In the current study, Pearson's correlation coefficients for the
C-SCCS and the PCSCCS-M were computed to assess the concurrent validity of the C-SCCS. To verify the quality of the component structure, we conducted a confirmatory factor analysis (CFA) based on other sampling data obtained from 354 nurses. We also tested the scale's internal consistency using Cronbach's alpha coefficient and the scale's stability using the Guttman split-half coefficient.

\section{Data collection}

For the data collection, a professional platform called 'SO JUMP' was used. ${ }^{38}$ The instruments used in the present study (the socialdemographic form, the C-SCCS and the PCSCCS-M) were distributed to the nurses as a set with an invitation to complete them. First, the content of the questionnaires was entered into the computer. Then, we distributed the questionnaires through personal WeChat messages (a total of 17 nurses) and 4 WeChat chat groups (group 1, 107 nurses; group 2, 161 nurses; group 3, 120 nurses and group 4, 412 nurses) over WhatsApp. Before participants completed the questionnaires, written consent forms were obtained.

\section{Statistical analysis}

IBM SPSS V.23.0 was used to perform the data analysis. Descriptive statistics were used to analyse the characteristics of the sample. An alpha level of 0.05 was used for the statistical tests. Item analysis was conducted using the following analyses: (a) criteria value (CR), (b) corrected item-total correlation, (c) factor loading, (d) Cronbach's alpha if an item was deleted and (e) theoretical considerations. In addition, items with a CR $<3.0$, a corrected item-total correlation $<0.30$ and whose deletion increased the value of the alpha coefficient for the overall scale by 0.5 or more were dropped. The internal consistency and homogeneity of the C-SCCS were assessed using Cronbach's alpha. Cronbach's alpha values $\geq 0.80$ indicate good internal consistency. The concurrent validity between the C-SCCS and the PCSCCS-M (Chinese version) was assessed by Pearson's correlation coefficient, with a $\mathrm{p}$ value $<0.05$ indicating a positive correlation. The C-SCCS's construct validity was analysed via EFA using principal axis factor analysis with oblique rotation if the correlation between the factors was $>0.3$ and principal component analysis with varimax rotation otherwise. Prior to performing EFA, the Kaiser-Meyer-Olkin (KMO) test (a test of sampling adequacy) and Bartlett's test of sphericity (a test of the suitability of the correlation matrix for factor analysis) were conducted. The criteria for factor extraction were an eigenvalue $>1.0$ and a factor loading $>0.40$. To assess the impact of the participants' characteristics on the outcomes, Student's t-test or the F test was used, and a $p$ value $<0.05$ was accepted as statistically significant.

A CFA was carried out using AMOS V.20.0 to further verify the construct validity of the C-SCCS. The results were reported using the Strengthening the Reporting 
of Observational Studies in Epidemiology cross-sectional study reporting guidelines. ${ }^{39}$

\section{Patient and public involvement}

No patients were involved in this study. The experts who consulted or translated the study and the nurses who completed the questionnaires were considered as a form of public involvement. No participants were involved in developing the questionnaire or designing or conducting the study. However, we plan to share the findings with several nurse managers so that they can understand nurses' spiritual care ability levels.

\section{RESULTS}

\section{Sample characteristics}

A total of 709 (out of a possible 800) nurses completed the survey (response rate: $88.63 \%$ ). All of the questionnaires obtained $(n=709)$ were suitable for this study. Fifty per cent of the sample was randomly selected for EFA $(\mathrm{n}=355)$, and the remaining samples were selected for CFA $(n=354)$. In the sample used for EFA, the majority of the nurses were female $(n=335,94.4 \%)$ and had an undergraduate education level $(73.2 \%)$. The average length of employment was 10.39 years (SD 8.84). The main characteristics of the participants whose data were used for EFA are illustrated in table 1.

\section{Psychometric analyses \\ Item analysis}

The internal consistency analysis of the 27-item C-SCCS showed that the average of each item score ranged from 3.63 to 4.21 . Item-total correlations ranged from 0.52 to 0.80 . Each corrected item-total correlation was positive, with values between 0.43 and 0.77 , showing moderate to strong correlation. All CR values were $>3.0$, ranging from 5.62 to 17.05 . The internal consistency of the 27 -item C-SCCS was satisfactory, with Cronbach's alphas of 0.93, 0.92 and 0.89 , and the deletion of any items in the scale would not have improved the Cronbach's alpha of the scale. The results of the item analysis indicated that no items needed to be deleted (table 2).

\section{Face validity, construct validity and concurrent validity}

To evaluate the face validity of the scale, the C-SCCS was given to 20 nurses from hospitals of three different levels to assess their interpretation of the scale items. The nurses stated that the wording of most of the C-SCCS items was easy to understand. EFA was used to evaluate the construct validity of the C-SCCS. Three distinct factors were extracted. This model could explain $58.19 \%$ of the total variance (table 3 ). In addition, the factor loading on all items was $>0.30$. The percentages of variance for the C-SCCS subscales are listed in table 4 . The correlation of the C-SCCS with the PCSCCS-M was 0.67 ( $\mathrm{p}<0.01$, table 5 shows this in more detail), demonstrating good concurrent validity.
Table 1 Social and demographic information of the participants $(n=355)$

\begin{tabular}{|c|c|c|}
\hline Variable & Number & $\begin{array}{l}\text { Per cent } \\
(\%)\end{array}$ \\
\hline \multicolumn{3}{|l|}{ Gender } \\
\hline Male & 20 & 5.6 \\
\hline Female & 335 & 94.4 \\
\hline \multicolumn{3}{|l|}{ Age, years } \\
\hline $18-26$ & 64 & 18.0 \\
\hline $27-31$ & 116 & 32.7 \\
\hline $31-40$ & 131 & 36.9 \\
\hline $41-50$ & 39 & 11.0 \\
\hline$\geq 51$ & 5 & 1.4 \\
\hline \multicolumn{3}{|l|}{ Education } \\
\hline Secondary vocational school & 2 & 0.6 \\
\hline Junior college & 68 & 19.2 \\
\hline Undergraduate & 260 & 73.2 \\
\hline Postgraduate or above & 25 & 7.0 \\
\hline \multicolumn{3}{|l|}{ Department } \\
\hline Internal medicine & 122 & 34.4 \\
\hline Surgical & 63 & 17.7 \\
\hline Paediatrics & 14 & 3.9 \\
\hline Obstetrics and gynaecology & 29 & 8.2 \\
\hline Emergency & 13 & 3.7 \\
\hline ICU & 12 & 3.4 \\
\hline Operating room & 4 & 1.1 \\
\hline Outpatient services & 14 & 3.9 \\
\hline Psychiatric & 41 & 11.5 \\
\hline Other & 43 & 12.1 \\
\hline \multicolumn{3}{|l|}{ Income ( $¥ /$ month ) } \\
\hline$<5000$ & 203 & 57.2 \\
\hline$\geq 5000$ & 152 & 42.8 \\
\hline Working years, years $(\mathrm{M} \pm \mathrm{SD})$ & 10.39 & $(8.84)$ \\
\hline
\end{tabular}

Internal consistency reliability, split-half reliability and model fit The KMO value of the C-SCCS was 0.95 , which was better than 0.50 (the minimal admissible level); the results of Bartlett's test of sphericity were also acceptable (approximate $\chi^{2}=6896.34, \mathrm{df}=351, \mathrm{p}<0.001$ ), showing the suitability of EFA. The EFA demonstrated that for the subscales for assessment, implementation, professionalisation and quality improvement of spiritual care (factor 1), personal and team support (factor 2) and attitude towards patient spirituality and communication (factor 3), the Cronbach's alpha coefficients were $0.93,0.92$ and 0.89 , respectively (table 4). Table 2 shows detailed information on the item analysis. The Guttman split-half coefficient of the C-SCCS was 0.84, indicating its adequate reliability. Table 6 shows the various indices of goodness-of-fit for the model of the present study and the original model of the SCCS based on the current sample data. The three-factor 
Table 2 Internal consistency of the C-SCCS $(n=355)$

\begin{tabular}{|c|c|c|c|c|c|c|c|}
\hline Items & Mean \pm SD & Critical ratio & $\begin{array}{l}\text { Item-total } \\
\text { correlation }\end{array}$ & $\begin{array}{l}\text { Adjusted item- } \\
\text { total correlation }\end{array}$ & $\begin{array}{l}\text { Cronbach's } \alpha \text { if } \\
\text { item deleted }\end{array}$ & $c^{2}$ & $\begin{array}{l}\text { Factor } \\
\text { loading }\end{array}$ \\
\hline C1 & $3.70 \pm 0.71$ & $12.68^{*}$ & $0.65^{*}$ & 0.59 & 0.95 & 0.43 & 0.49 \\
\hline $\mathrm{C} 2$ & $3.92 \pm 0.57$ & $8.75^{\star}$ & $0.68^{\star}$ & 0.63 & 0.95 & 0.44 & 0.59 \\
\hline C3 & $3.91 \pm 0.57$ & $10.33^{*}$ & $0.71^{*}$ & 0.66 & 0.95 & 0.51 & 0.66 \\
\hline $\mathrm{C} 4$ & $3.80 \pm 0.70$ & $11.28^{\star}$ & $0.68^{*}$ & 0.63 & 0.95 & 0.48 & 0.57 \\
\hline C5 & $3.67 \pm 0.77$ & $15.24^{*}$ & $0.71^{*}$ & 0.67 & 0.95 & 0.52 & 0.63 \\
\hline $\mathrm{C} 6$ & $3.75 \pm 0.74$ & $11.60^{*}$ & $0.69^{*}$ & 0.64 & 0.95 & 0.51 & 0.59 \\
\hline $\mathrm{C} 7$ & $3.82 \pm 0.67$ & $13.51^{*}$ & $0.80^{\star}$ & 0.77 & 0.95 & 0.69 & 0.71 \\
\hline $\mathrm{C} 8$ & $3.90 \pm 0.65$ & $12.23^{*}$ & $0.78^{*}$ & 0.74 & 0.95 & 0.63 & 0.65 \\
\hline C9 & $3.89 \pm 0.61$ & $10.88^{*}$ & $0.74^{*}$ & 0.70 & 0.95 & 0.59 & 0.63 \\
\hline C10 & $3.89 \pm 0.63$ & $10.52^{*}$ & $0.72^{*}$ & 0.67 & 0.95 & 0.60 & 0.79 \\
\hline C11 & $3.84 \pm 0.65$ & $11.43^{*}$ & $0.73^{\star}$ & 0.69 & 0.95 & 0.58 & 0.81 \\
\hline $\mathrm{C} 12$ & $3.85 \pm 0.65$ & $13.16^{*}$ & $0.76^{\star}$ & 0.72 & 0.95 & 0.59 & 0.76 \\
\hline $\mathrm{C} 13$ & $3.98 \pm 0.62$ & $11.05^{*}$ & $0.77^{*}$ & 0.73 & 0.95 & 0.60 & 0.63 \\
\hline C14 & $3.87 \pm 0.66$ & $11.76^{*}$ & $0.78^{*}$ & 0.74 & 0.95 & 0.61 & 0.64 \\
\hline C15 & $3.66 \pm 0.81$ & $14.85^{*}$ & $0.73^{*}$ & 0.69 & 0.95 & 0.65 & 0.71 \\
\hline C16 & $3.63 \pm 0.85$ & $13.63^{*}$ & $0.69^{*}$ & 0.64 & 0.95 & 0.68 & 0.74 \\
\hline C17 & $3.86 \pm 0.72$ & $13.11^{*}$ & $0.76^{\star}$ & 0.72 & 0.95 & 0.56 & 0.60 \\
\hline C18 & $3.71 \pm 0.81$ & $12.33^{*}$ & $0.68^{*}$ & 0.63 & 0.95 & 0.67 & 0.73 \\
\hline C19 & $3.78 \pm 0.77$ & $17.05^{\star}$ & $0.76^{\star}$ & 0.73 & 0.95 & 0.66 & 0.70 \\
\hline C20 & $3.69 \pm 0.81$ & $14.06^{*}$ & $0.71^{*}$ & 0.66 & 0.95 & 0.74 & 0.77 \\
\hline $\mathrm{C} 21$ & $3.73 \pm 0.71$ & $12.64^{*}$ & $0.69^{*}$ & 0.64 & 0.95 & 0.50 & 0.58 \\
\hline $\mathrm{C} 22$ & $4.05 \pm 0.63$ & $6.87^{\star}$ & $0.57^{\star}$ & 0.50 & 0.95 & 0.50 & 0.62 \\
\hline $\mathrm{C} 23$ & $4.08 \pm 0.60$ & $6.40^{*}$ & $0.55^{\star}$ & 0.48 & 0.95 & 0.56 & 0.65 \\
\hline C24 & $4.21 \pm 0.55$ & $5.620^{*}$ & $0.52^{*}$ & 0.43 & 0.95 & 0.64 & 0.72 \\
\hline $\mathrm{C} 25$ & $4.06 \pm 0.61$ & $7.56^{\star}$ & $0.64^{*}$ & 0.57 & 0.95 & 0.55 & 0.62 \\
\hline C26 & $4.12 \pm 0.58$ & $7.01^{*}$ & $0.63^{*}$ & 0.57 & 0.95 & 0.62 & 0.68 \\
\hline $\mathrm{C} 27$ & $4.12 \pm 0.55$ & $7.31^{*}$ & $0.59^{\star}$ & 0.52 & 0.95 & 0.63 & 0.69 \\
\hline
\end{tabular}

${ }^{*} P<0.01$. Cronbach's $\alpha=0.95$; Guttman split-half coefficient $=0.84$; Spearman-Brown coefficient $=0.84$.

$\mathrm{C}^{2}$, communalities; SCCS, Chinese version of Spiritual Care Competency Scale.

model of the C-SCCS showed a more adequate fit than the six-factor model, but the fit indices of both models were ideal.

Table 7 shows the association between the nurses' demographic variables and the three factors of the C-SCCS. We found significant associations between the nurses' education level and factor 2, 'personal and team support' $(\mathrm{F}=3.394, \mathrm{p}=0.018)$. The nurses with a junior college or undergraduate-level education appeared to score higher on the factor 'personal and team spiritual support'. The post hoc analysis showed a significantly higher proportion of junior college-educated and undergraduate-educated nurses than of nurses with a graduate-level education and above who were competent in providing personal and team spiritual support for patients (mean difference $(\mathrm{I}-\mathrm{J})$, 3.94; $\mathrm{p}=0.008$ for junior college-educated nurses

Table 3 Total variance explained using exploratory factor analysis

\section{Initial eigenvalues}

\begin{tabular}{lrr}
\cline { 2 - 3 } Factor & Total & \% of variance \\
\hline 1 & 12.44 & 46.09 \\
2 & 2.53 & 9.37 \\
3 & 1.93 & 7.13
\end{tabular}

\section{Extraction sums of squared loading}

\begin{tabular}{lrrlll} 
Cumulative \% & & Total & \% of variance & Cumulative \% & Total \\
\hline 46.09 & 12.03 & 44.55 & 44.55 & 11.08 \\
55.45 & 2.12 & 7.87 & 52.42 & 8.80 \\
62.59 & 1.56 & 5.77 & 58.19 & 6.77 \\
\hline
\end{tabular}
loading

Rotation sums of squared 


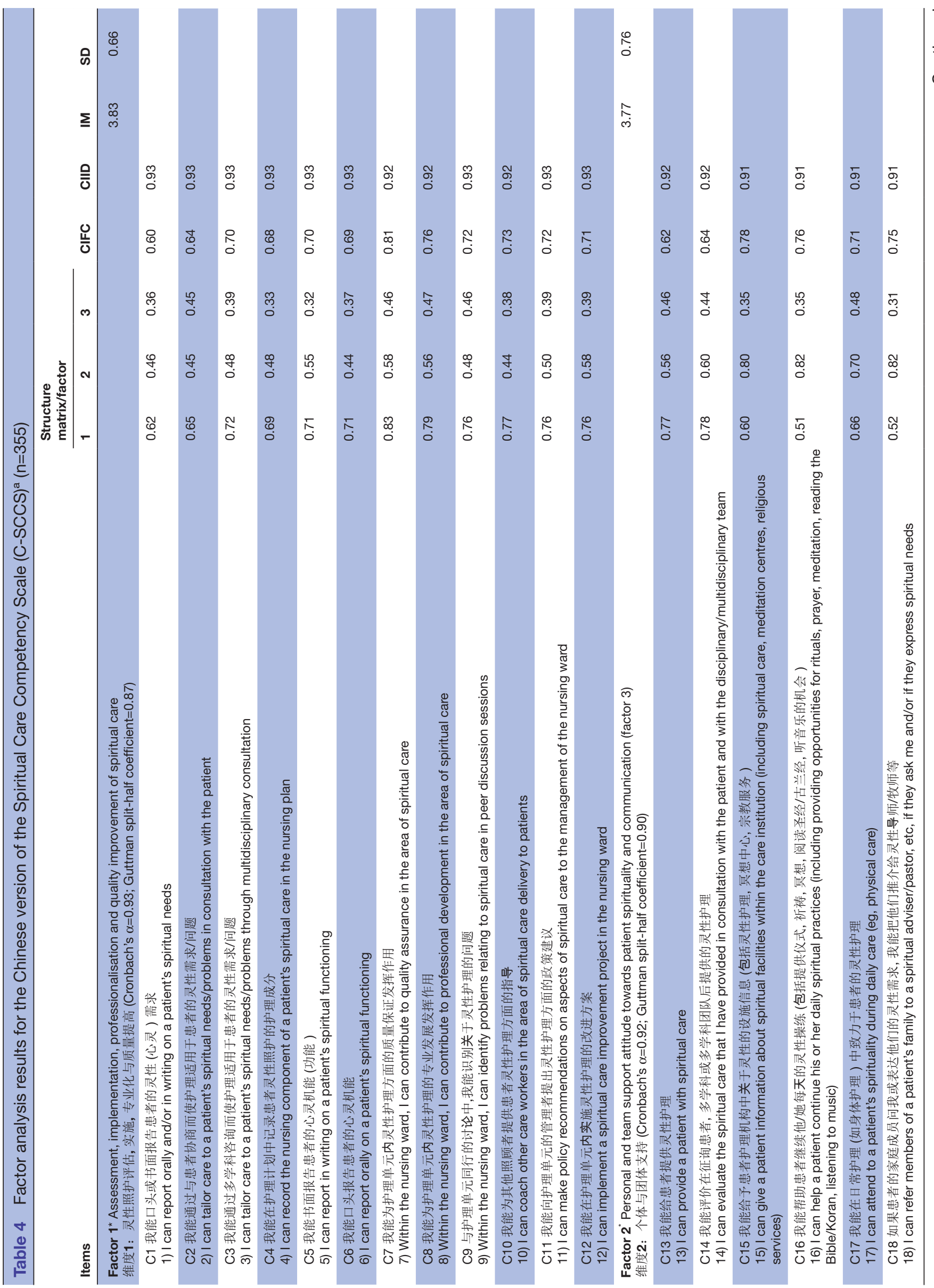




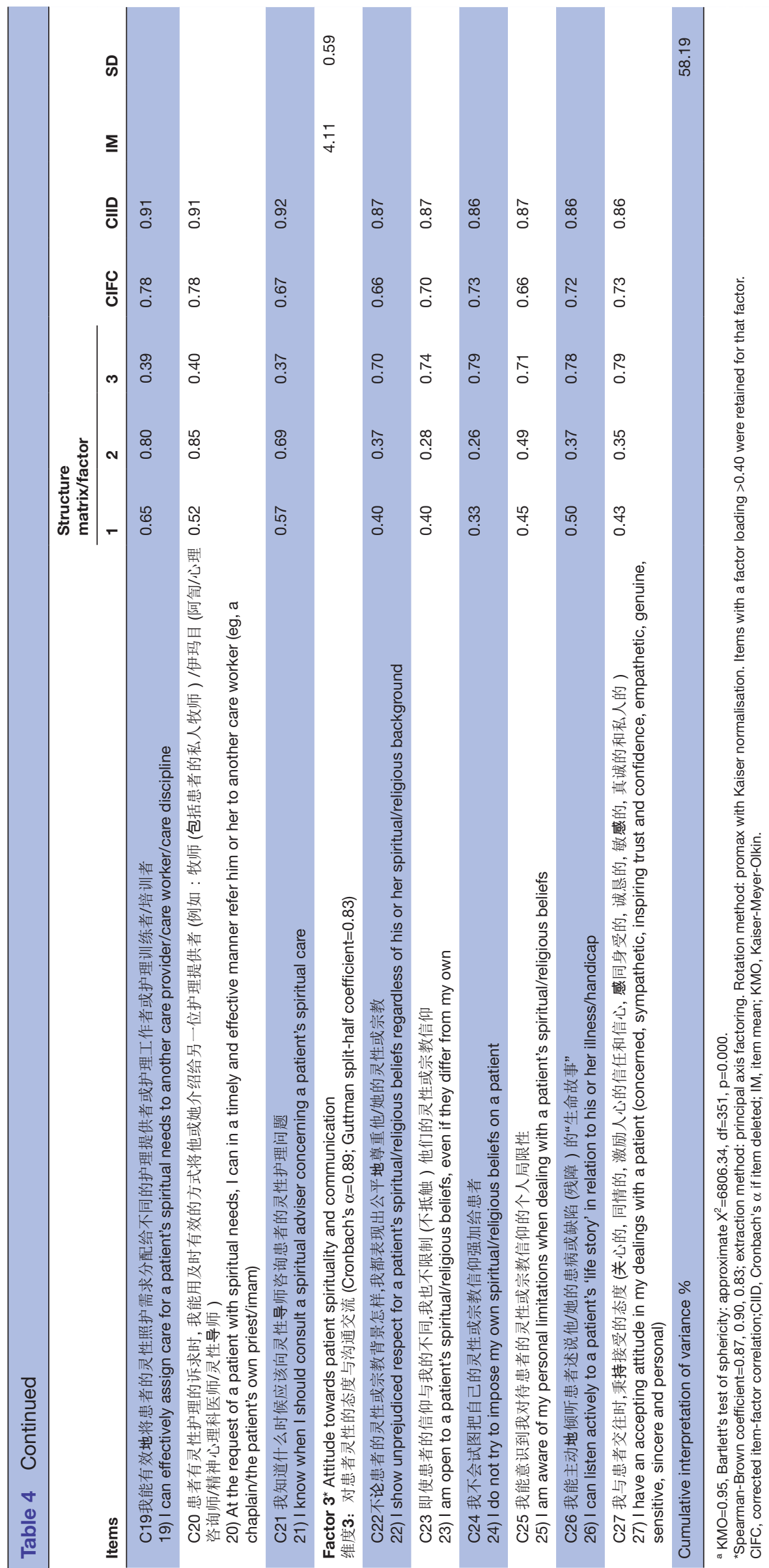


Table 5 Cronbach's alpha and Pearson's product-moment correlations between the C-SCCS and PCSCCS-M

\begin{tabular}{|c|c|c|c|c|c|c|c|c|}
\hline Measures & C-SCCS & Factor 1 & Factor 2 & Factor 3 & PCSCCS-M & PCSCCS-M 1 & PCSCCS-M 2 & PCSCCS-M 3 \\
\hline C-SCCS & $\alpha=0.95$ & & & & & & & \\
\hline Factor 1 & $0.93^{\star \star}$ & $\alpha=0.93$ & & & & & & \\
\hline Factor 3 & $0.68^{\star \star}$ & $0.51^{\star \star}$ & $0.49^{\star \star}$ & $\alpha=0.89$ & & & & \\
\hline PCSCCS-M & $0.67^{\star \star}$ & $0.60^{\star \star}$ & $0.63^{\star \star}$ & $0.45^{\star \star}$ & $\alpha=0.93$ & & & \\
\hline PCSCCS-M 2 & $0.62^{\star \star}$ & $0.56^{\star \star}$ & $0.53^{\star \star}$ & $0.54^{\star *}$ & $0.90^{\star \star}$ & $0.69^{\star \star}$ & $\alpha=0.89$ & \\
\hline PCSCCS-M 3 & $0.57^{\star \star}$ & $0.50^{\star \star}$ & $0.59^{\star \star}$ & $0.31^{\star \star}$ & $0.91^{\star \star}$ & $0.65^{\star \star}$ & $0.70^{* \star}$ & $\alpha=0.87$ \\
\hline
\end{tabular}

Pearson's correlation coefficient test was used, two-tailed. Cronbach's alpha values are on the diagonal. SCCS: assessment, implementation, professionalisation and quality improvement of spiritual care (factor 1), personal and team support (factor 2) and attitude towards patient spirituality and communication (factor 3). PCSCCS-M: self-awareness of spiritual care (PCSCCS-M 1), nurses' perceived knowledge about spiritual care (PCSCCS-M 2) and attitudes about spiritual care (PCSCCS-M 3).

${ }^{* *} \mathrm{p}<0.01$.

C-SCCS, Chinese version of SCCS; PCSCCS-M, Palliative Care Spiritual Care Competency Scale; SCCS, Spiritual Care Competency Scale.

compared with nurses with a graduate-level education and above; mean difference (I-J): 2.90; $\mathrm{p}=0.009$ for undergraduate-educated nurses compared with nurses with a graduate-level education and above). Surprisingly, lower-income nurses scored higher than those earning an average of RMB 5000 or more per month in all aspects of their spiritual care competencies. Neither gender, age nor working years was associated with nurses' abilities to provide spiritual care.

\begin{tabular}{|c|c|c|c|}
\hline $\begin{array}{l}\text { Model fit } \\
\text { summary }\end{array}$ & $\begin{array}{l}\text { Standard } \\
\text { model fit }\end{array}$ & $\begin{array}{l}\text { Adjusted } \\
\text { model fit }\end{array}$ & Ideal value \\
\hline CMIN/df & 4.209 & 2.263 & $\leq 3$ \\
\hline RMR & 0.034 & 0.03 & $<0.1$ \\
\hline RMSEA & 0.095 & 0.06 & $0.05-0.08$ \\
\hline GFI & 0.78 & 0.88 & $\geq 0.85$ \\
\hline AGFI & 0.74 & 0.85 & $\geq 0.80$ \\
\hline $\mathrm{NFI}$ & 0.80 & 0.90 & $\geq 0.90$ \\
\hline RFI & 0.78 & 0.88 & $\geq 0.90$ \\
\hline $\mathrm{IFI}$ & 0.84 & 0.94 & $\geq 0.90$ \\
\hline TLI & 0.82 & 0.93 & $\geq 0.90$ \\
\hline $\mathrm{CFI}$ & 0.84 & 0.94 & $\geq 0.90$ \\
\hline PNFI & 0.73 & 0.74 & $>0.50$ \\
\hline PCFI & 0.77 & 0.77 & $>0.50$ \\
\hline
\end{tabular}

AGFI, adjusted goodness-of-fit index; CFI, comparative-of-fit index; CMIN/df, Chi-square goodness-of-fit test; GFI, goodnessof-fit index; IFI, incremental-of-fit index; NFI, normal-of-fit index; PCFI, parsimony comparative-of-fit index; PNFI, parsimony normed-of-fit index; RFI, Relative-of-fit index; RMR, root of the mean square residual; RMSEA, root mean square error of approximation; TLI, Tucker-Lewis index.

\section{DISCUSSION}

The main purpose of this current study was to translate the English version of the well-validated SCCS into Chinese and to examine the reliability and validity of the C-SCCS. The sample for this study was selected from 10 different types of locations, including hospitals of different levels and various departments. To some extent, the results should represent a variety of nurses with diverse backgrounds. As a whole, in our study sample, the C-SCCS showed good face validity, construct validity, concurrent validity and internal consistency.

Compared with the original English version of the SCCS, the C-SCCS performed well, with Cronbach's alpha coefficients of $0.93,0.92$ and 0.89 for the three subscales. These Cronbach's alpha values were higher than those of the six-domain model of the English version, which were $0.82,0.82,0.81,0.79,0.56$ and 0.70 . Over $58 \%$ of the total variance could be explained by the current three-factor model, better than the 53\% shown in the English version. The split-half internal consistency measure of the scale revealed a correlation of 0.84 between the two halves, which also proved the sound reliability of the C-SCCS. In addition, the C-SCCS showed significantly moderate levels of concurrent validity with the PCSCCS-M, indicating that these measures have unique constructs. There was a minor difference between the number of factors extracted in the present study and that reported in studies conducted by van Leeuwen et $a l,{ }^{18}$ who performed an EFA on 27 items and obtained 6 common factors. However, the Chinese version and the English version had the same number of items in each subscale, which was consistent with the theoretical structure of the original scale. Therefore, there was no barrier to naming each factor, and they were labelled as follows: assessment, implementation, professionalisation and quality improvement of spiritual care (SCCS 1), personal and team support (SCCS 2) and attitude towards patient spirituality and communication (SCCS 3). 
Table 7 Association between the Chinese version of the Spiritual Care Competency Scale and patient characteristics

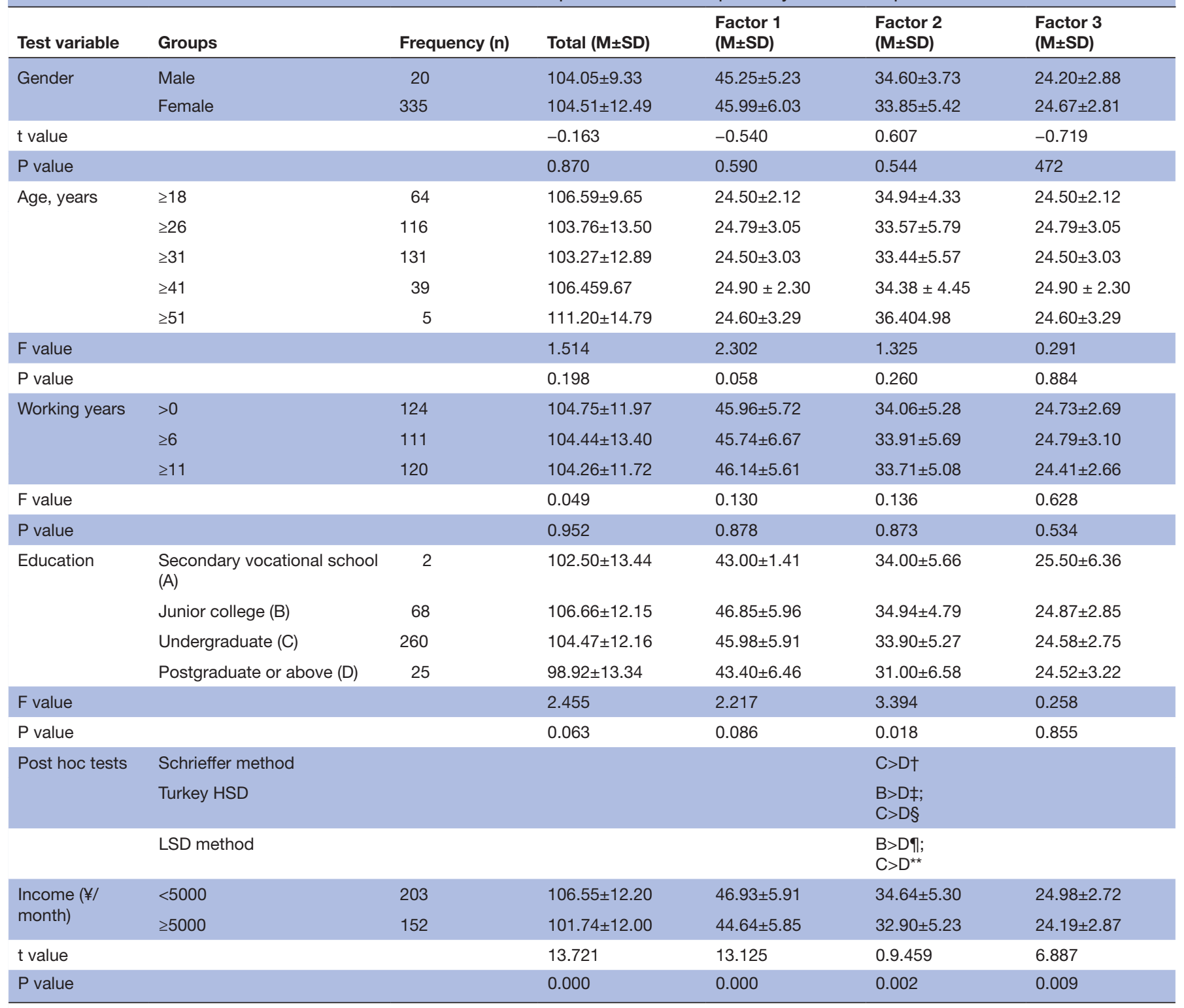

†Mean difference $(\mathrm{I}-\mathrm{J}), 3.94 ; \mathrm{SE}=1.24 ; \mathrm{p}=0.018$.

¥Mean difference $(I-J): 3.94 ; \mathrm{SE}=1.24 ; \mathrm{p}=0.008$

SMean difference $(\mathrm{I}-\mathrm{J}): 2.90 ; \mathrm{SE}=1.11 ; \mathrm{p}=0.045$.

IMean difference $(I-J): 3.94 ; S E=1.24 ; p=0.002$

** Mean difference $(I-J): 2.90 ; \mathrm{SE}=1.11 ; \mathrm{p}=0.009$.

HSD, honestly significant difference; LSD, least significant difference.

In addition, the C-SCCS showed good concurrent validity, with a connection between the PCSCCS-M that evaluated an identical feature. Statistically significant correlations between the C-SCCS and the PCSCCS-M ( $\mathrm{r}=0.67, \mathrm{p}<0.01)$ were found. Therefore, it can be concluded that the C-SCCS was sensitive enough to evaluate features similar to those evaluated by the PCSCCS-M.

Regarding the translation equivalence of the C-SCCS, most of the items appeared to have culturally equivalent terms in Chinese, and we were able to complete the translation without too much further cultural adaptation. There were two exceptions. One was the concept of 'spiritual'. We formulated and modified some of the expressions, such as 'mind', 'mental' and 'psych-', replacing them with 'spiritual', in accordance with Dr van Leeuwen's recommendation and the concept of mental health. ${ }^{40}$ The other exception was that, to adapt to the different cultural background, we used the Chinese words '心灵', which translate to 'spiritual care', in some sentences at the suggestion of several of the experts.

Given the evidence supporting the advantages of recognising nurses' capabilities in providing spiritual care, the number of studies assessing spiritual care has increased in recent years. Although some of these studies show that spiritual care can improve patients' health outcomes, this aspect of care has not been given adequate attention in 
nursing practice. Barriers to research on spiritual care may include the nurses being underprepared for this aspect of their role, their lack of confidence, their perceived incompetence in providing spiritual care and the inadequacy of the education they received. ${ }^{194142}$ To optimally deliver such care to patients, nurses need to be knowledgeable about this topic and should receive education or training to become more knowledgeable. Identifying these issues using an instrument proven to be valid by the current study will allow nurses to explore the resources available to assist them in improving their expertise in spiritual care to meet patients' spiritual needs.

Although the SCCS primarily targeted nursing students, it was found to be a valid and reliable multidimensional tool for Chinese clinical nursing staff with multicultural backgrounds to assess nurses' competencies in the provision of spiritual care. Evaluations using this tool will allow managers to formulate strategies to provide nurses with the spiritual care skills required to practice optimally and to assist nurses in improving their care quality.

Importantly, our results also revealed that nurses with lower levels of education (junior college and undergraduate) scored higher on the C-SCCS. Additionally, junior college-educated and undergraduate-educated nurses had significantly higher levels of spiritual care competence than nurses with a graduate-level education or above. This difference may be due to the small sample of nurses with a graduate or above education. However, there may be other reasons for this difference that should be explored. Additionally, higher-income nurses scored lower than those earning an average of less than RBM 5000 per month in all aspects of their ability to provide patients with spiritual care. This result was unexpected but may be because higher-income nurses generally live in densely populated metropolitan areas where consumption levels and life pressures are generally higher, offsetting their seemingly higher incomes. In addition, large hospitals in large cities are generally larger in scale, with more patients and a shortage of nurses, causing the workload of nurses to be higher and leaving no time and energy for them to provide spiritual care for patients.

\section{Study limitations and directions for future research}

There are several limitations. First, because a sample of nurses mainly from Henan Province and Jilin Province of China was recruited and the nurses' data in the present study were obtained using a convenience sampling method, the findings may not represent all nurses in China. Second, the use of the online-based questionnaire format instead of the original paper-based C-SCCS could lead to differences in validity between the online and paper forms. The use of an online questionnaire could also influence the responses due to unfamiliarity with online questionnaires and potential errors in responding using a mobile device. There are some implications for future research. The PCSCCS-M was chosen to evaluate the concurrent validity of the C-SCCS. The PCSCCS-M measures palliative caregivers' perceived awareness, ability and attitudes with respect to spirituality and spiritual care. There was moderate concurrent validity between the C-SCCS and the PCSCCS-M. Future studies could attempt to establish a structural equation model (SEM) to further analyse the factors influencing nurses' spiritual care perceptions and competencies and their relationships.

The study findings provided further support for the validity and reliability of the SCCS and its usefulness as a tool to measure nurses' competencies in spiritual care. The modified model showed good fit (CMIN/ $\mathrm{df}=2.26$; $\mathrm{RMR}=0.03$; root mean square error of approximation=0.06; GFI=0.88; AGFI=0.85; $\mathrm{IFI}=0.94$; TLI=0.93; table 6). However, the online supplementary figure also shows that the model may have multicollinearity due to cross-loading and may need further modification. Future research should enlarge the sample size and use exploratory structural equation modelling, ${ }^{43}{ }^{44}$ which may integrate features of EFA, CFA and SEM to overcome some of the limits of a single CFA.

\section{CONCLUSIONS}

Overall, the translated C-SCCS showed good reliability and validity in our study sample. It was found to be a potentially useful instrument for measuring nurses' perceived spiritual care competency in China. Further analysis using multiple methods would help to establish the stability of this instrument. Recruitment of a larger sample that is more representative of the Chinese nursing population and applications of the C-SCCS in other settings or to other healthcare providers are necessary in the future.

\section{Author affiliations}

${ }^{1}$ School of Nursing, Jilin University, Changchun, China

${ }^{2}$ Health Care, Viaa Christian University of Applied Sciences, Zwolle, The Netherlands ${ }^{3}$ The Key Laboratory for Bionics Engineering, Ministry of Education, Jilin University, Changchun, China

${ }^{4}$ Engineering Research Center for Medical Biomaterials of Jilin Province, Jilin University, Changchun, China

${ }^{5}$ Key Laboratory for Biomedical Materials of Jilin Province, Jilin University, Changchun, China

${ }^{6}$ State Key Laboratory of Pathogenesis, Prevention and Treatment of High Incidence Diseases in Central Asia, Xinjiang University, Xinjiang, China

${ }^{7}$ Department of Pathogenobiology, The Key Laboratory of Zoonosis Research, Chinese Ministry of Education, College of Basic Medicine, Jilin University, Changchun, China

Acknowledgements The authors would like to thank Yingying Li and Wanhong Wei, who contacted the author of the SCCS to obtain permission to translate it, reviewed the translated version of the SCCS and assisted in the data collection. The authors would like to thank Feng Li, Gaojie Yue, Ying Chen, Cancan Chen and Jianmei Gong for their assistance with the verification and modification of the translated version of the SCCS. The authors would like to thank Xiaohui Liu, Cancan Chen and Caihua Tian for their assistance with the data collection. The authors would also like to thank the nurses who agreed to participate in the study.

Contributors YH led the analysis plan, conducted the data analysis, interpreted the findings and drafted the manuscript. RvL confirmed and modified the backtranslated version of the SCCS, reviewed the manuscript, revised it critically for important intellectual content and edited it to ensure readability in English. FL was responsible for the study design, supervised the study, led the data collection, 
contacted experts to translate and revise the manuscript and approved the final draft.

Funding This work was supported by grants from the National Natural Science Foundation of China (\#81320108025 and \#81672109) and the Graduate Innovation Fund of Jilin University (101832018C088).

Disclaimer The funding agencies did not have any role in the design of the study; the collection, analysis and interpretation of the data or the writing of the manuscript.

\section{Competing interests None declared.}

Patient consent for publication Not required.

Ethics approval The present study has been reviewed and approved by the Institute Review Board of the College of Nursing, Jilin University (access number: 2018031101).

Provenance and peer review Not commissioned; externally peer reviewed.

Data availability statement Data are available on reasonable request.

Open access This is an open access article distributed in accordance with the Creative Commons Attribution Non Commercial (CC BY-NC 4.0) license, which permits others to distribute, remix, adapt, build upon this work non-commercially, and license their derivative works on different terms, provided the original work is properly cited, appropriate credit is given, any changes made indicated, and the use is non-commercial. See: http://creativecommons.org/licenses/by-nc/4.0/.

ORCID iD

Fan Li http://orcid.org/0000-0002-1517-616X

\section{REFERENCES}

1 Chochinov HM. Dying, dignity, and new horizons in palliative end-oflife care. Ca Cancer J Clin 2006;56:84-103.

2 Daaleman TP, Usher BM, Williams SW, et al. An exploratory study of spiritual care at the end of life. Ann Fam Med 2008;6:406-11.

3 Grassi L, Costantini A, Caruso R, et al. Dignity and PsychosocialRelated variables in advanced and Nonadvanced cancer patients by using the patient dignity Inventory-Italian version. J Pain Symptom Manage 2017;53:279-87.

4 VanderWeele TJ, Balboni TA, Koh HK. Health and spirituality. JAMA 2017:318:519-20.

5 Johnson JR, Engelberg RA, Nielsen EL, et al. The association of spiritual care providers' activities with family members' satisfaction with care after a death in the ICU*. Crit Care Med 2014;42:1991-2000.

6 Pearce MJ, Coan AD, Herndon JE, et al. Unmet spiritual care needs impact emotional and spiritual well-being in advanced cancer patients. Support Care Cancer 2012;20:2269-76.

$7 \mathrm{Hu} \mathrm{Y,} \mathrm{Liu} \mathrm{T,} \mathrm{Li} \mathrm{F.} \mathrm{Association} \mathrm{between} \mathrm{dyadic} \mathrm{interventions} \mathrm{and}$ outcomes in cancer patients: a meta-analysis. Support Care Cancer 2019;27:745-61.

8 Ross L, McSherry W, Giske T, et al. Nursing and midwifery students' perceptions of spirituality, spiritual care, and spiritual care competency: a prospective, longitudinal, correlational European study. Nurse Educ Today 2018;67:64-71.

9 van de Geer J, Groot M, Andela R, et al. Training hospital staff on spiritual care in palliative care influences patient-reported outcomes: results of a quasi-experimental study. Palliat Med 2017;31:743-53.

10 Mackinlay E, Trevitt C. Living in aged care: using spiritual reminiscence to enhance meaning in life for those with dementia. Int J Ment Health Nurs 2010;19:394-401.

11 Ødbehr LS, Hauge S, Danbolt LJ, et al. Residents' and caregivers' views on spiritual care and their understanding of spiritual needs in persons with dementia: A meta-synthesis. Dementia 2017;16:911-29.

12 Brennan F. Holistic Palliative Care approach - physical, spiritual, religious and psychological needs. Nephrology 2013.

13 Ronaldson S, Hayes L, Aggar C, et al. Spirituality and spiritual caring: nurses' perspectives and practice in palliative and acute care environments. J Clin Nurs 2012;21:2126-35.

14 Addressin C. Dying in America: improving quality and honoring individual preferences near the end of life. Mil Med 2015;180:365-7.

15 Kavalieratos D, Corbelli J, Zhang D, et al. Association between palliative care and patient and caregiver outcomes: a systematic review and meta-analysis. JAMA 2016;316:2104-14.

16 Zimmermann C, Swami N, Krzyzanowska M, et al. Early palliative care for patients with advanced cancer: a cluster-randomised controlled trial. The Lancet 2014;383:1721-30.
17 Chen J, Lin Y, Yan J, et al. The effects of spiritual care on quality of life and spiritual well-being among patients with terminal illness: a systematic review. Palliat Med 2018;32

18 van Leeuwen $R$, Tiesinga LJ, Middel $B$, et al. The validity and reliability of an instrument to assess nursing competencies in spiritual care. J Clin Nurs 2009;18:2857-69.

19 O'Brien MR, Kinloch K, Groves KE, et al. Meeting patients' spiritual needs during end-of-life care: A qualitative study of nurses' and healthcare professionals' perceptions of spiritual care training. J Clin Nurs 2019;28:182-9.

20 Best M, Butow P, Olver I. Palliative care specialists' beliefs about spiritual care. Support Care Cancer 2016;24:3295-306.

21 Selman LE, Brighton LJ, Sinclair S, et al. Patients' and caregivers' needs, experiences, preferences and research priorities in spiritual care: A focus group study across nine countries. Palliat Med 2018;32:216-30.

22 Ross L, Giske T, van Leeuwen R, et al. Factors contributing to student nurses'/midwives' perceived competency in spiritual care. Nurse Educ Today 2016;36:445-51.

23 Paal P, Helo Y, Frick E. Spiritual care training provided to healthcare professionals: a systematic review. J Pastoral Care Counsel 2015;69:19-30.

24 Yardley SJ, Walshe CE, Parr A. Improving training in spiritual care: a qualitative study exploring patient perceptions of professional educational requirements. Palliat Med 2009;23:601-7.

25 Daudt H, d'Archangelo M, Duquette D. Spiritual care training in healthcare: does it really have an impact? Palliative and Supportive Care 2018;17:1-9.

26 Yang GM, Tan YY, Cheung YB, et al. Effect of a spiritual care training program for staff on patient outcomes. Pall Supp Care 2017:15:434-43.

27 Sai L, Qinqin C, Yongyi Y, et al. Research status of spiritual care education. Journal of Nursing Science 2016;2016:94-7.

28 Gallison BS, Xu Y, Jurgens CY, et al. Acute care nurses' spiritual care practices. J Holist Nurs 2013;31:95-103.

29 Petersen CL, Callahan MF, McCarthy DO, et al. An online educational program improves pediatric oncology nurses' knowledge, attitudes, and spiritual care competence. J Pediatr Oncol Nurs 2017;34:130-9.

30 Meyer CL. How effectively are nurse educators preparing students to provide spiritual care? Nurse Educ 2003;28:185-90.

31 Chen P-H, Chiou J-F, Chu MC, et al. D07-B the development of the palliative care spiritual care competency scale. J Pain Symptom Manage 2016;52:e33.

32 van Leeuwen R, Cusveller B. Nursing competencies for spiritual care. $J$ Adv Nurs 2004;48:234-46.

33 Baldacchino DR. Nursing competencies for spiritual care. J Clin Nurs 2006;15:885-96.

34 Wittich W, Höbler F, Jarry J, et al. Recommendations for successful sensory screening in older adults with dementia in long-term care: a qualitative environmental scan of Canadian specialists. BMJ Open 2018;8:e019451.

$35 \mathrm{Hu}$ Y, Li F, Chiou J-F. Psychometric properties of the Chinese mainland version of the palliative care spiritual care competency scale (PCSCCS-M) in nursing: a cross-sectional study. BMC Palliat Care 2019;18:27.

36 Brislin RW. The wording and translation of research instruments 1986;8:137-64.

37 Chung MJ, Park Y, Eun Y. Validity and reliability of Korean version of the spiritual care competence scale. J Korean Acad Nurs 2016;46:871-91.

38 So jump. Available: https://www.wjx.cn/?source=baidu\&plan=\%E9\% 97\%AE\%E5\%8D\%B7\%E6\%98\%9F\&keyword=\%E9\%97\%AE\% $\mathrm{E} 5 \% 8 \mathrm{D} \% \mathrm{~B} 7 \% \mathrm{E} 6 \%$ 98\%9FBH

39 von Elm E, Altman DG, Egger M, et al. The strengthening the reporting of observational studies in epidemiology (STROBE) statement: guidelines for reporting observational studies. J Clin Epidemiol 2008;61:344-9.

40 Vaingankar JA, Subramaniam M, Tan LWL, et al. Psychometric properties and population norms of the positive mental health instrument in a representative multi-ethnic Asian population. BMC Med Res Methodol 2018;18:29.

41 Bar-Sela G, Schultz MJ, Elshamy K, et al. Human development index and its association with staff spiritual care provision: a middle Eastern oncology study. Support Care Cancer 2019;27:3601-10.

$42 \mathrm{Hu} \mathrm{Y,} \mathrm{Tiew} \mathrm{LH,} \mathrm{Li} \mathrm{F.} \mathrm{Psychometric} \mathrm{properties} \mathrm{of} \mathrm{the} \mathrm{Chinese} \mathrm{version}$ of the spiritual care-giving scale (C-SCGS) in nursing practice. BMC Med Res Methodol 2019;19:21.

43 Asparouhov T, Muthén B. Exploratory structural equation modeling. Structural Equation Modeling: A Multidisciplinary Journal 2009;16:397-438. 
44 Marsh HW, Morin AJS, Parker PD, et al. Exploratory structural equation modeling: an integration of the best features of exploratory and confirmatory factor analysis. Annu Rev Clin Psychol 2014;10:85-110. 